\title{
REASONS AND OUTCOMES OF ADMISSIONS TO THE MEDICAL WARDS OF JIMMA UNIVERSITY SPECIALIZED HOSPITAL, SOUTHWEST ETHIOPIA
}

\author{
Elias Ali ${ }^{1}, \mathrm{MD}$, Mirkuzie Woldie ${ }^{2}{ }^{*}, \mathrm{MD}, \mathrm{MPH}$
}

\section{ABSTRACT}

BACKGROUND: Non-communicable diseases are the main reasons for admission to the medical wards in high-income countries. While in low and middle income countries communicable diseases are the main reasons for admission to the medical wards. However, in some low and middle income countries the reasons for admission are changing from communicable diseases to noncommunicable diseases. But, data on reasons for admission to the medical wards of low income countries is scarce. Therefore, this study takes one year data from a low income country referral hospital aiming at describing the recent reasons and outcomes of medical admissions to see whether there is a change in reasons for admission and the outcome.

METHODS: A retrospective study examined patient case notes and ward registration books of medical admissions at Jimma University Specialized Hospital from January 1, 2008 to December 31, 2008. Socio-demographic variables, reasons and outcomes of admission were some of the variables recorded during the data collection. The International Statistical Classification of Disease was used for sorting and categorizing the diagnosis. The data was then analyzed using SPSS windows version 13.0.

RESULT: A total of 610 patient case notes were reviewed. The mean age of the patients was 36 years (SD \pm 15.75). The highest number of admissions 218 (35.7\%) was among the age groups 21 to 30 years. Communicable diseases; namely severe community acquired pneumonia 139(22.8\%), all infectious and parasitic diseases category 100 (16.4\%), and pyogenic as well as chronic meningitis $\mathbf{8 0}(13.1 \%)$ were the most common reasons for admission. The death rate among patients admitted to the medical wards was $12.6 \%$.

CONCLUSIONS: Communicable diseases were still the common reasons for medical admissions at Jimma University Specialized Hospital. The outcome of medical admissions has not changed over sixteen years.

KEY WORDS: Patient, admissions, reasons, medical outcomes

\section{INTRODUCTION}

The decision to admit patients to the medical wards is determined by age, co-existing illness (co-morbidity), physical and laboratory findings, the ability of the patient to comply reliably with an oral medication, and the resources available to the patient outside the hospital (1).

In studies done in developed countries, medical admissions accounted for $22.2 \%, 33.0 \%$, and $13.0 \%$ of total hospital admissions in U.S.A, Western Australia and Hong Kong, respectively (2-4). Whereas, in a South African study admissions to the medical wards constituted $40 \%$ of the total hospital admissions (5).

In developed countries Non-communicable diseases namely cardiovascular diseases are the main reasons for medical admissions.. For instance, In the Australian study, the most common reason for admissions to the medical wards was cardiovascular disease, $29 \%$ (3). In another study, admissions to medical wards at a hospital in Hong Kong were most frequently associated with the cardiovascular system which made up $30.3 \%$ of all medical cases (4).

\footnotetext{
${ }^{1}$ Department of Pharmacology, Jimma University, P.O. Box 1637 Jimma, Ethiopia, E-mail: eliasaliyesuf@yahoo.com

${ }^{2}$ Department of Health Services Management, Jimma University, P.O. Box 1637, Jimma, Ethiopia, E-mail: mirkuzie@yahoo.com

* Corresponding Author
} 
However, in cities and towns of developing countries, the increasing urbanization and westernization of the population is changing the morbidity pattern of diseases (6-9). It is becoming widely accepted that noncommunicable or chronic diseases are also now the major causes of death and disability in low and middle income countries (10-12). Despite a decrease in life expectancy because of the HIV epidemic in some Sub-Saharan African countries (13), populations are ageing in low and middle income countries. Moreover, health care to prevent and control these diseases is expensive and unavailable, and the inhabitants are increasingly exposed to risk factors (14). In particular, smoking is increased in underdeveloped countries. The annual cigarette consumption per adult (in cigarettes) has increased from 860 in the early 1970 s to 1410 in 1995. The reason was aggressive marketing of tobacco companies, delay in implementing antismoking regulations, and because of the public perception of the risk of smoking is still low (15).

This has been supported by studies from South Africa. Circulatory disorders (22\%) and infectious diseases $(19 \%)$ were shown to be the main causes for admission to medical wards of GF Jooste Hospital (5). In another study from the same country medical admissions were mostly associated with the circulatory system (27.9\%) followed by respiratory $(15.9 \%)$ and infectious diseases (11.9\%) (8).

Unlike the findings in developed and some SubSaharan African countries, the leading reasons for admission to the medical wards in Ethiopia were found to be communicable diseases. Particularly, communicable diseases such as acute febrile illness of infectious origin, pneumonia and tuberculosis were the reasons for admisson to the medical wards (16).

Referral hospitals are often a highly specific focal point for disease-specific health promotion and education (17). Even though review of records of referral hospital admissions may not indicate the actual prevalence of diseases in the community; it will provide clues about the changing pattern of diseases affecting the community. Unfortunately, data on the specific diseases that indicate reasons for admission to referral hospitals in Ethiopia and their outcomes is scarce. In a study which was undertaken 16 years ago a 2 year record (between Sep 1993 and August 1995) of admission to the medical wards of Jimma University Specialized hospital (JUSH) was reviewed. This study found infectious diseases as the major reasons for admission and a high mortality rate of $12.3 \%$ (16). But this study lacks the assessment of complications which are very important in understanding the mortality in hospitals. In addition, this study didn't determine the relationship between the reasons for admission and socio-demographic variables such as sex, and place of residence. It also lacked the assessment of outcomes in relation to hospital stay. Therefore, the objective of this study was to describe the reasons and outcomes of admissions to the medical wards of JUSH.

\section{METHODS}

A retrospective cross-sectional study was conducted from May 16 to May 26, 2009 on patients who were admitted to the medical wards of Jimma University Specialized Hospital from January 1, 2008 to December 31, 2008. The hospital serves about 11 million people living within a very wide catchment area of about 250 $\mathrm{km}$ radius. It is a training center for about 700 health sciences students each year. The hospital has four major (Medical, Surgery, Gynecology/ obstetrics, and pediatrics) and five other departments. The hospital provides postgraduate training in Internal Medicine, Surgery, Gynecology/ obstetrics, Pediatrics, and Ophthalmology. It has 450 beds and a total of more than 550 employees. Internal medicine department has 67 beds. The main diagnostic modalities in the hospital are routine laboratory investigations, radiology and histo-pathologic techniques.

All patients who were admitted to the medical wards of JUSH during the study period (January.1, 2008 to December. 31, 2008) and whose case notes were available in the hospital registration room archive were included. Case notes were classified according to year of admission. The recent case notes of patients admitted to the medical wards in the year 2008 were retrieved. Hence, all cases found during the study period were included in the study and no sampling technique was used. The dependent variables in this study were reasons for admission and outcome of admission, while the explanatory variables included socio-demographic characteristics of the patients in the case notes reviewed, co-morbidities, complications, duration of hospital stay and month of admission.

During data collection case notes of patients admitted to the medical wards and ward registration book were reviewed by two nurses. The data collectors were oriented on completing the structured data collection format prepared for the study. The data collection format included socio-demographics of the respondents, the reason for admission, the co-morbidities, duration of hospital stay, and complications where they develop in the hospital or present from the outset. The format also included outcome variables like discharge with improvement, transfer to other wards, referral to other hospitals, and death. These outcome variables were documented from the registration book and then sorted using International Classification of Diseases (ICD) ten version 2007 (18). Patient case notes with incomplete information were excluded from the study. Then the data obtained was entered into 
SPSS version 13.0 and analysis was done to obtain descriptive measures. Finally, $\mathrm{X}^{2}$ testes of association were done at a significance level of 0.05 wherever appropriate.

Before starting data collection letter of support was obtained from the student research program and permission was obtained from the hospital administration. Moreover, confidentiality of personal information was maintained during data collection, analysis, and interpretation. The following operational definitions were used in the study:

- Reason for admission: is the primary diagnosis given to the illness of the patient by the physician when the patient was admitted.

- Co-morbidity: is an illness which had occurred with the primary diagnosis during the time of admission

- Complications: Severe symptoms of the disease which could lead to death unless treated.

- Season of admission: the particular time (month) of the year during which the patient was admitted.

- Outcome of admission: is diagnosis at discharge.

\section{RESULTS}

A total of 1400 patients were admitted to the medical wards during the one year period. Of these, $614(44.0 \%)$ case notes of patients were available for review. Among these 326 (53.1\%) were men and the male to female ratio was 1.1 to 1. The age of the patients ranged from 14 to 90 . The mean age of the patients was 36 years ( $\mathrm{SD} \pm$ 15.75). The highest number of admissions came from the age group of 21 to 30 years, 221 $(36.0 \%)$. The patients were predominantly, 362 $(59.0 \%)$ from the rural areas (Table 1).

It was found that the most common reasons for admission to the medical wards of JUSH were diseases of the respiratory system, 164 (26.9\%) followed by infectious and parasitic diseases, 100 $(16.4 \%)$, diseases of the nervous system, 88 $(14.4 \%)$, and diseases of the circulatory system, $178(12.8 \%)$. In the category of the respiratory system diseases the major subcategory were community acquired pneumonia, 139 (84.8\%) followed by pneumocystic carinii pneumonia and chronic lower respiratory diseases each accounting for, $9(5.5 \%)$ of the admissions in this category (Table 2).

Table 1. Socio-demographic characteristics of the patients admitted to JUSH, Southwest Ethiopia, 2008

\begin{tabular}{|c|c|c|}
\hline Sociodemographic variable & $(n=614)$ & Number $(\%)$ \\
\hline \multicolumn{3}{|l|}{ Sex of the patient } \\
\hline Male & & $326(53.1 \%)$ \\
\hline Female & & $288(46.9 \%)$ \\
\hline \multicolumn{3}{|l|}{ Place of residence } \\
\hline Urban & & $252(41 \%)$ \\
\hline Rural & & $362(59 \%)$ \\
\hline \multicolumn{3}{|l|}{ Age category of the patients } \\
\hline $14-20$ & & $89(14.5 \%)$ \\
\hline $21-30$ & & $221(36 \%)$ \\
\hline $31-40$ & & $123(20 \%)$ \\
\hline $41-50$ & & $84(13.7 \%)$ \\
\hline $51-60$ & & $49(8 \%)$ \\
\hline Above 60 & & $48(7.8 \%)$ \\
\hline
\end{tabular}

Malaria and tuberculosis were the major subcategories in the infectious and parasitic diseases category accounting for, $52(52.0 \%)$ and $33(33.0 \%)$ of admission in this category, respectively. Moreover, meningitis (mainly pyogenic) is the single most common subcategory, $80(91.0 \%)$ of diseases of the central nervous system (Table 2). 
Table 3. Association of the sex of the patients with the reasons for admission to the medical wards of JUSH, South west Ethiopia. 2008

\begin{tabular}{|c|c|c|c|c|}
\hline \multirow[t]{2}{*}{ ICD category } & \multirow[t]{2}{*}{ Reason for admission } & \multicolumn{2}{|c|}{ sex } & \multirow[b]{2}{*}{ p-value } \\
\hline & & $\begin{array}{c}\text { Male } \\
\text { N }(\%)\end{array}$ & $\begin{array}{c}\text { Female } \\
\mathrm{N}(\%)\end{array}$ & \\
\hline $\mathrm{A}$ or $\mathrm{B}$ & Infectious and parasitic disease & 40 & 60 & \\
\hline $\mathrm{C}$ & Malignant neoplasms & 1 & 3 & \\
\hline $\mathrm{D}$ & anemia & 17 & 22 & \\
\hline $\mathrm{E}$ & Endocrine, Nutritional, and Metabolic disease & 8 & 3 & \\
\hline G & Diseases of the nervous system & 49 & 39 & \\
\hline I & Diseases of the circulatory system & 54 & 23 & 0.007 \\
\hline $\mathrm{J}$ & Diseases of the respiratory system & 89 & 75 & \\
\hline K & Diseases of the digestive system & 32 & 24 & \\
\hline M & Spondilopathies and other MSS disorders & 5 & 4 & \\
\hline $\mathrm{N}$ & Diseases of the genitourinary system & 27 & 34 & \\
\hline \multirow[t]{2}{*}{$\mathrm{O}$} & Miscellanious conditions & 4 & 1 & \\
\hline & Total & 326 & 614 & \\
\hline
\end{tabular}

$X^{2}$ test value $=25.5$

Regarding the co-morbidities seen at the medical wards, $446(73.1 \%)$ of patients had co-morbidity at admission. The co-morbidities are mainly in the infectious and parasitic diseases category, 264 $(59.2 \%)$ followed by diseases of the circulatory system, $58(13.0 \%)$ and the digestive system, 42 (9.4\%). Tuberculosis alone accounted for $25.9 \%$ of the co-morbidities making it the major comorbidity followed by Human ImmuneDeficiency Virus (HIV) infection (12.3\%) (Fig.1). At the time of presentation or following admission $425(69.7 \%)$ of the patients had complications. From these, $360(84.7 \%)$ had only one complication and the remaining 65 (15.3\%) patients were found to have more than one complications. The main complications seen at the medical wards include congestive heart failure, pleural effusion, anemia, and opportunistic infections and immune reconstitution inflammatory syndrome (IRIS) of HIV/AIDS each accounting for $59(9.7 \%), 50$ $(8.2 \%), 46(7.5 \%)$, and $39(6.4 \%)$ of the complications, respectively (Fig.2)

Regarding the hospital stay of patients, 237 $(39.3 \%)$ patients stayed in the hospital for five to ten days, $224(36.9 \%)$ for more than ten days, while the remaining145 $(23.8 \%)$ had a hospital stay less than five days.

Table 4. Association of hospital stay with the outcome of patients admitted to the medical wards of JUSH, southwest Ethiopia, 2008*

\begin{tabular}{lcccc}
\hline Out come & \multicolumn{3}{c}{ Hospital stay } \\
\cline { 2 - 4 } & $<5$ days & $5-10$ days & $>10$ days & \\
Improved \& discharged & 86 & 188 & 183 & p-value \\
Same and discharged & 5 & 16 & 9 & $=0.000$ \\
Self discharge & 10 & 11 & 9 & \\
Referred & 3 & 5 & 4 & \\
\hline Died & 41 & 17 & 19 \\
\hline
\end{tabular}

$X^{2}$ test value $=71.23$

*some diseases e.g. spondilopathies which have contributed to a very small number of admissions were excluded from this analysis 
Table 2. Reasons for admission of patients to the medical wards of JUSH, South west Ethiopia, 2008

\begin{tabular}{|c|c|c|c|}
\hline ICD category* & Reasons for admission & Number & Percent \\
\hline \multirow[t]{6}{*}{$\mathrm{A}$ or $\mathrm{B}$} & Certain infectious and parasitic diseases & 100 & 16.4 \\
\hline & Malaria & 52 & 8.5 \\
\hline & Tuberculosis & 33 & 5.4 \\
\hline & Human immunodeficiency virus (HIV) disease & 4 & 0.7 \\
\hline & Relapsing fever & 3 & 0.5 \\
\hline & Others ${ }^{\dagger}$ & 8 & 1.3 \\
\hline $\mathrm{C}$ & Malignant Neoplasms & 4 & 0.7 \\
\hline $\mathrm{D}$ & Anemia & 31 & 5.1 \\
\hline \multirow[t]{3}{*}{$\mathrm{E}$} & Endocrine, nutritional and metabolic disease & 11 & 1.8 \\
\hline & Diabetes Mellitus & 7 & 1.2 \\
\hline & Others ${ }^{*}$ & 4 & 0.7 \\
\hline \multirow[t]{4}{*}{ G } & Diseases of the Nervous system & 88 & 14.4 \\
\hline & Pyogenic and chronic Meningitis & 80 & 13.1 \\
\hline & Polyneuropathies & 6 & 1.0 \\
\hline & Others ${ }^{\S}$ & 2 & 0.4 \\
\hline \multirow[t]{7}{*}{$\mathrm{I}$} & Diseases of the circulatory system & 78 & 12.8 \\
\hline & Cerebrovascular diseases & 20 & 3.3 \\
\hline & Valvular heart diseases and cardiomyopathies & 18 & 3.0 \\
\hline & Hypertensive diseases & 13 & 2.1 \\
\hline & Ischaemic heart diseases & 11 & 1.8 \\
\hline & Corpulmonale & 10 & 1.6 \\
\hline & Others $\|$ & 6 & 1.1 \\
\hline \multirow[t]{6}{*}{$\mathrm{J}$} & Diseases of the respiratory system & 164 & 26.9 \\
\hline & Severe community Acquired Pneumonia & 139 & 22.8 \\
\hline & Pneumocystis carinii pneumonia & 9 & 1.5 \\
\hline & Chronic lower respiratory diseases & 9 & 1.5 \\
\hline & Acute upper respiratory infections & 4 & 0.7 \\
\hline & Others ${ }^{\text {f }}$ & 3 & 0.6 \\
\hline \multirow[t]{5}{*}{$\mathrm{K}$} & Diseases of the Digestive system & 56 & 9.2 \\
\hline & Chronic liver disease & 22 & 3.6 \\
\hline & Peritonitis & 21 & 3.4 \\
\hline & Acute gastroenteritis & 9 & 1.5 \\
\hline & Others ${ }^{* *}$ & 4 & 0.7 \\
\hline M & Spondylopathies and other MSS diseases & 9 & 1.5 \\
\hline \multirow[t]{5}{*}{$\mathrm{N}$} & Diseases of the genitourinary system & 61 & 10.0 \\
\hline & Renal failure & 28 & 4.6 \\
\hline & Urinary tract infections & 17 & 2.8 \\
\hline & Glomerular diseases & 12 & 2.0 \\
\hline & Others $^{\dagger \dagger}$ & 4 & 0.7 \\
\hline $\mathrm{O}$ & Miscellaneous conditions & 12 & \\
\hline \multicolumn{4}{|c|}{ * ICD $=$ International Classification of Diseases and related health problems } \\
\hline \multicolumn{4}{|c|}{$\dagger=$ protozoal diseases } \\
\hline \multicolumn{4}{|c|}{$*$ malnutrition } \\
\hline \multicolumn{4}{|c|}{$\S_{1}=$ nerve, nerve root, and plexus disorders not specifically diagnosed } \\
\hline \multicolumn{4}{|c|}{$\|_{=}$acute rheumatic fever, deep venous thrombosis } \\
\hline \multicolumn{4}{|c|}{$q=$ Lung abscess } \\
\hline \multicolumn{4}{|c|}{${ }^{* *}=$ non-infective colitis, acute gastritis, chronic gastritis } \\
\hline$\dagger=$ Other Diso & rders of genito-urinary tract whose diagnoses is $n$ & cifi & \\
\hline
\end{tabular}

With regard to the outcome of admissions to the medical wards, four hundred and fifty seven $(75.0 \%)$ patients were discharged with improvement. While $77(12.6 \%)$ patients died in the hospital. Patients who had been discharged with the outcome of the same, self discharge, and referral to other hospitals have together accounted for the remaining $76(12.4 \%)$ of the cases.

The association of sex and place of residence of the patients with the reasons for admission, and the association of hospital stay and the outcome of admission was assessed using chi-square test at a significance level of 0.05 . 
(CLRD) Chronic lower respiratory disease

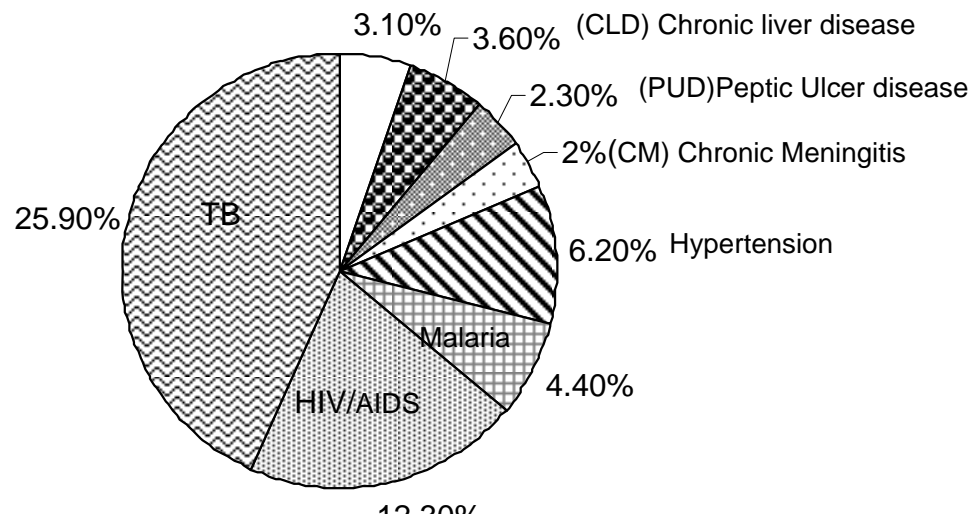

$12.30 \%$

Figure 1 The major co-morbidities of patients admitted to the medical wards of JUSH, Southwest Ethiopia, 2008.

In the top three major reasons for admission males have out-numbered females except in the infectious and parasitic diseases category. It was also observed that there is a strong association between sex of the patients and the reasons for admission $(p$-value $=0.009)$ (Table 3$)$.

However, no significant association $(p=0.951)$ was found between reasons of admission and place of residence.

Majority of the patients $41(53.0 \%)$ who died in the hospital stayed for less than 5 days in the hospital. It was also found that there is a strong association between hospital stay and outcomes of admission ( $p$-value $=0.000$ ) (Table 4).

\section{DISCUSSION}

The results of this study have shown that communicable diseases were the major reasons for medical admissions at JUSH. Besides, the outcomes of medical admissions have not changed over a decade and six years.

The results of this study indicated that patients admitted to the medical wards were mostly between 21 and 30 years (young adults). These results are in line with findings from other studies carried out elsewhere in Ethiopia (16).
However, in South African and Nigerian studies, it was observed that patients admitted to the medical wards were mostly people older than 40 years of age $(5,20)$. This could be explained by the difference in the population composition of the countries.

In contrast to JUSH where communicable diseases are found to be the main reasons for admission, non-communicable diseases are the main reasons for admission at certain referral hospitals of middle income countries. Circulatory disorders are the main reasons for medical admissions at GF Jooste Hospital (South Africa), Queen Mary Hospital (Hong Kong), and Hillbrow Hospital (South Africa) accounting for $22.0 \%, \quad 40.0 \%$, and $27.9 \%$ of medical admissions, respectively $(4,5,8)$. The difference from the current study might be due to a change in disease pattern from communicable to noncommunicable diseases in the urban areas of developing countries (6-9).In South Africa, unhealthy lifestyles, such as tobacco use, unhealthy nutrition, and lack of regular aerobic physical activity have contributed for increased admissions due to cardiovascular system diseases (21). Such change might be absent in Ethiopia. 


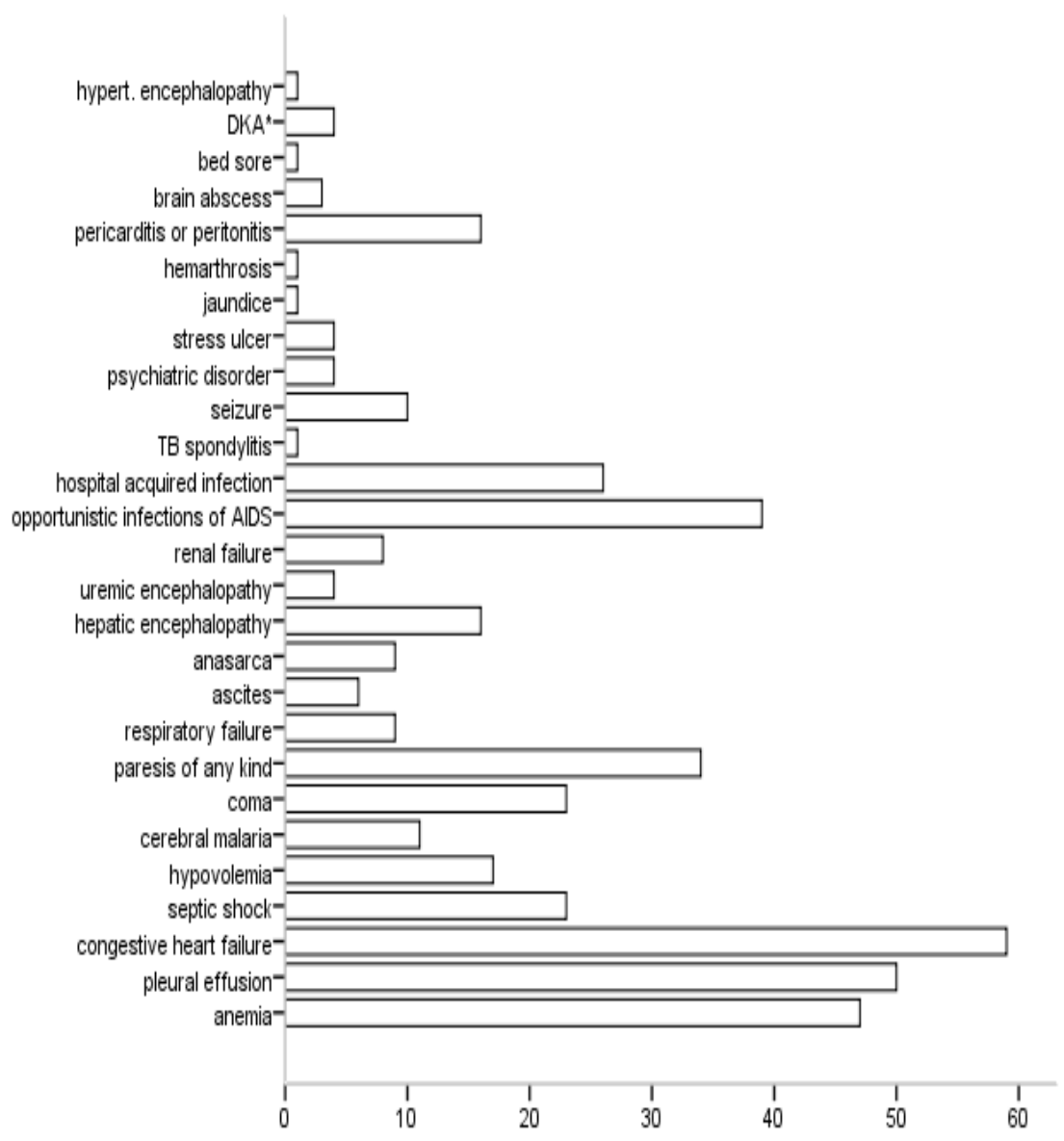

*DKA=Diabetes Keto-Acidosis

Figure 2. The main complications in patients admitted to the medical wards of JUSH, southwest Ethiopia, 2008.

The death rate $(12.6 \%)$ was similar to the findings of a previous study in Jimma Hospital 16 years ago (12.3\%) (16). This maintained death rate can partially be explained by the presence of severe complications such as congestive heart failure, hepatic encephalopathy, opportunistic infections of HIV/AIDS among patients admitted to the medical wards. Moreover, in this study $53.0 \%$ of patients who died stayed for less than 5 days in the hospital, this early death within few days of admission could be due to the severity of the diseases at the time of presentation to the hospital $(16,20)$.

The hospital administration and all concerned bodies should note that the death rate in the hospital has not changed over 16 years. Having all the advances in medical care during this period measures should be introduced to ensure that improvements in services provided lead to better outcomes in patients served by the hospital. Moreover, since $75.0 \%$ of the patients who died in the hospital have died within 10 days of admission we recommend further study to understand the reasons contributing for the death of patients within 10 days of admission to the medical wards.

Finally, inability to include all case notes due to lose of the documents and including only one year data are the limitations of this study.

\section{ACKNOWLEDGEMENTS}

The authors would like to acknowledge Jimma University for funding this study.

\section{REFERENCES}

1. Mandell LA, Wunderink R. CommunityAcquired Pneumonia: Treatment, Site of Care. In: Kasper LD, Braunwald E, Fauci AS, Hauser LS, Longo LD, Jameson JL, editors. Harrison's 
Principles of Internal Medicine. $17^{\text {th }}$ ed. New York: McGraw-Hill; 2008. Pp.1622-1623

2. Cordle F, Tyroler HA. The use of Hospital medical records for epidemiologic research. 1. Differences in Hospital Utilization and in hospital mortality by age- race-sex- place of residence and socioeconomic status in a defined community population. Medical care. 1974 ; 12: 596-610.

3. Saint EG. Medical morbidity in a general hospital. Med J Aust. 1960;2: 601-608.

4. Pan JC, cheung TD, Chau Y.N. Hospital, medical and cardiovascular disease admissions in a Hong Kong Hospital. Bulletin Hong Kong Medical Association. 1982; 34: 55-62.

5. Marszalek J, De villiers PJ. Morbidity Profile of admissions to GF Jooste Hospital, Manenberg, Cape Town. SA Fam Pract. 2006; 48(6): 15-15e.

6. Mudiayi TK, Onyanga- Omara A, Gelman ML. Trends of morbidity in general medicine at United Bulawayo Hospital, Bulawayo, Zimbabwe. The central African Journal of medicine. 1997; 43(8): 213-8.

7. Mayet GHF. Lifestyle and disease: Disease patterns in Indian South Africans. S Afr Med J. 1982; 61: 96872.

8. Dean MPG, Gear JSS. Medical admissions to Hillbrow Hospital, Johannesburg, by discharge diagnosis. S Afr Med J. 1986;69: 672-3.

9. Benator SR, Saven A. Morbidity trends in the medical wards at Groote Schuur Hospital 1971 and 1982. S Afr Med J. 1985; 67: 968 -74.

10. Miranda JJ, Patel V. Achieving the Millennium Development Goals: Does Mental Health play a Role? PLos Medicine. 2005; 2(10): e291.

11. Perel P, Casas JP, Ortiz Z, Miranda JJ, Non communicable diseases and injuries in Latin America and the Caribbean. Time for Action. PLos Medicane. 2006; 3(9): 344.

12. World Health Organization. Preventing Chronic Diseases: A vital investment. WHO Global Report. Geneva: World Health Organization, 2005.

13. USAIDS. Report on the global HIV/AIDS epidemic 2002.Geneve, 2002. P.45.Available at: http://www.unaids.org

14. Valleron AJ. Mortality and morbidity worldwide, now and tomorrow: what is known? CR Biol. 2008 Dec; 331 (12): 991-1006.

15. Abdullah AS, Hustein CG. Promotion of smoking cessation in developing countries: a framework for urgent public health interventions. Thorax 2004; 59: 623-630.

16. Hussein K. Pattern of Medical Admissions to Jimma Hospital. Bull Inst Health Sci. 1997; 7(1): 51-62.

17. Hensher M, Price M, Adomakoh S. Referral Hospitals. In: Jamison DT, Breman JG, Measham AR, Alleyne G, Claeson M, Evans DB, editors. Disease control priorities in developing countries. New York: Oxford University Press; 2006. p. 1229.

18. Central Statistical Services. International Statistical Classification of Diseases and Related Health Problems, ICD. $10^{\text {th }}$ revision, 2007 Jan: 1-62.

19. Habte -Gabr E, Girma B, Mehrete M, Mehari A, Tekle E, Belachew K, et al. Analysis of Admissions to Gondar Hospital in NorthWestern Ethiopia, 1971-1972. Ethiop Med J. 1976; 14:4959.

20. Garko SB, Ekweani CN, Anyiam CA. Duration of Hospital stay and Mortality in the medical wards of Ahmadu Bello University Teaching Hospital, Kaduna, Nigera. Annals of African Medicine. 2003; 2(2): 68-71.

21. South African Medical Research Council [Internet] Cape Town: The Council: [updated 2010 Feb 25; cited 2010 Feb 25]. Available from: http//www.mrc.ac.za/chronic/col/19952005.htm. 